\title{
Ord. Prof. Dr. Kemal Cenap Berksoy ve Türk Fizyolojisindeki Önemi
}

\author{
Distinguished Prof. Dr. Kemal Cenap Berksoy and His Importance in Turkish \\ Physiology \\ Görkem Melike ARKAN ${ }^{1}$ (D), Fuat İNCE ${ }^{2 *}$ (D) , Mustafa SAYGIN ${ }^{10}$
}

${ }^{1}$ Süleyman Demirel Üniversitesi, Tıp Fakültesi, Fizyoloji Anabilim Dalı, Isparta, Türkiye

${ }^{2}$ Süleyman Demirel Üniversitesi, Tıp Fakültesi, Tıp Tarihi ve Etik Anabilim Dalı, Isparta, Türkiye

\begin{abstract}
Ö Z E T
Dünyada fizyoloji ile ilgili ilk çalışmalar 16. Yüzyılda, Türkiye'de ise 19. yüzyılda Batı'daki gelişmeleri anlamak ve takip etmek için yurt dışına gönderilen akademisyenlerin ülkemize dönmeleriyle başlamıştır. Kemal Cenap Berksoy, tıp eğitimi alırken fizyolojiye ilgi duymaya başlamıştır. Berksoy, fizyoloji alanında Türkiye'de ilk çalışmaları yapan hekimlerden biri olan Mehmed Şakir'in asistanlığını yaptığı dönemde ilk fizyoloji çalışmalarına başlamıştır. Ordinaryüs Profesör Doktor Kemal Cenap Berksoy, fizyoloji biliminin Türkiye'de tanınması ve ilerlemesi için çalışmalar, araştırmalar yapmıştır. Yurt dışında birlikte çalıştığı bilim insanlarından edindiği bilgileri ve orada gerçekleştirdiği çalışmalarda elde ettiği tecrübeleri, hem ülkemizdeki diğer akademisyenlerle hem de kendi öğrencileri ile paylaşmış; yurt dışındaki bazı bilim insanlarının çalışmalarını Türkiye'de tekrar etmiştir. Yurt içi çalışmalarını yaptığı dönemlerde üniversitelerde fizyoloji ile ilgili Türkçe yayınların yetersizliği nedeniyle çalışmalarını kitap haline getirmiş ve akademik dünyanın kullanımına sunmuştur. Akademik yayınlarının yanı sıra görev aldığı kürsüde hekimler yetiştirmiştir. Kemal Cenap Berksoy, uzun bir dönem boyunca Nobel Fizyoloji ve Tıp Ödülleri'ne aday gösterilen Türkiye'deki tek bilim insanımız olmuştur. Berksoy'un hayatı, eğitimi, akademisyenliği ve milletvekilliği dönemlerinin ayrı ayrı incelenmesi gerekir. Bu dönemler incelendiğinde Kemal Cenap Berksoy'un Türk Fizyolojisindeki önemi anlaşılabilir.
\end{abstract}

Anahtar Kelimeler: Kemal Cenap Berksoy, fizyoloji, tıp tarihi, Nobel Fizyoloji ve Tıp Ödülleri

Alınış / Received: 14.06.2021 Kabul / Accepted: 10.08.2021 Online Yayınlanma / Published Online: 20.12.2021 


\section{0}

A B S T R A C T

The first studies on physiology in the world began in the 16th century. The first studies in the physiology in Turkey started with the return of academics who were sent abroad to understand and follow the developments in the West in the 19th century. Kemal Cenap Berksoy became interested in physiology while studying medicine. Berksoy started his first physiology studies when he was the assistant of Mehmed Şakir, who was one of the first physicians to conduct studies in the field of physiology in Turkey. Distinguished Professor Doctor Kemal Cenap Berksoy has conducted studies and researches for the promotion and advancement of physiology science in Turkey. He shared the knowledge he gained from the scientists he worked with abroad and the experiences he gained in the studies he carried out there, both with other academicians in our country and with his own students; He repeated the studies of some scientists abroad in Turkey. During his domestic studies, due to the inadequacy of Turkish publications on physiology at universities, he compiled his studies into a book and made them available to the academic world. In addition to his academic publications, he has trained physicians in his chair. Kemal Cenap Berksoy has been our only scientist in Turkey to be nominated for the Nobel Prize in Physiology and Medicine for a long time. Berksoy's life, education, academic and parliamentary periods should be examined separately. When these periods are examined, the importance of Kemal Cenap Berksoy in Turkish Physiology can be understood.

Keywords: Kemal Cenap Berksoy, physiology, history of medicine, Nobel Prize in Physiology and Medicine

\section{Giriş}

Fizyoloji, yaşamın dinamik çalışmasını ve canlı maddenin işlevlerini inceleyen bir bilim dalıdır [1,2]. Fizyolojinin tanımını birkaç farklı şekilde yapabiliriz. Bu tanımlardan biri; fizyolojinin canlı organizmaların ve onların organlarının, hücrelerinin ve moleküllerinin hayati işlevlerini anlamamızı sağlayan bir bilim dalı olduğudur [1].

Türk Fizyolojik Bilimler Derneğine göre fizyoloji, en anlaşılabilir tanımıyla, "yaşamın mantığını araştıran" bir bilim dalıdır. "Yunanca doğa anlamına gelen "physis" kelimesi ile, bilim anlamına gelen "logos" kelimesinin birleşmesi ile ortaya çıkmış olan fizyoloji terimi, moleküler düzeyden hücre, doku, organ, sistem ve organizma düzeylerine kadar fonksiyonu ve bu fonksiyonun altında yatan mekanizmaları araştırır" [3,4].

Fizyoloji; biyokimya, biyofizik ve sinirbilimin disiplinlerini ve ayrıca ilgili bilimsel toplumlar ve dergilerinin disiplinlerini doğuran birkaç biyolojik bilimin annesidir [1]. Bu yüzden tıp biliminin ilk dallarından biri olan fizyolojinin bu alanındaki önemi yadsınamaz [5].

Fizyolojinin, Türk tarihindeki gelişimini anlayabilmek için kısa bir inceleme yapmamız gerekmektedir. Dünya tıp tarihinde fizyolojiyle ilgili ilk eser 16. yüzyılda basılmıştır. Türkiye'deyse 19. yüzyılda Hekimbaşı Mustafa Behçet Efendi tarafından Tercüme-i Fisiologia adlı çeviri eser yayımlanmıştır. Bu eserin önemi sadece ilk yayımlanan eser olmasından değil aynı zamanda Türkçeye bazı fizyoloji terimlerini kazandırmış olmasından kaynaklanmaktadır. Mustafa Behçet Efendi Türkiye'deki Batı modelli ilk tıp okulu olan Tıphane-i Amirenin kurucusudur ve bu okulun ders programında fizyoloji dersine de yer verilmiştir. Fizyoloji dersleri ilk başta, aslında göz hekimi olan Behçet Ata Efendi 
tarafından verilmiş olsa da zaman içerisinde bu alana özel eğitimler alan kişiler tarafından verilmeye başlanmıştır [6,7].

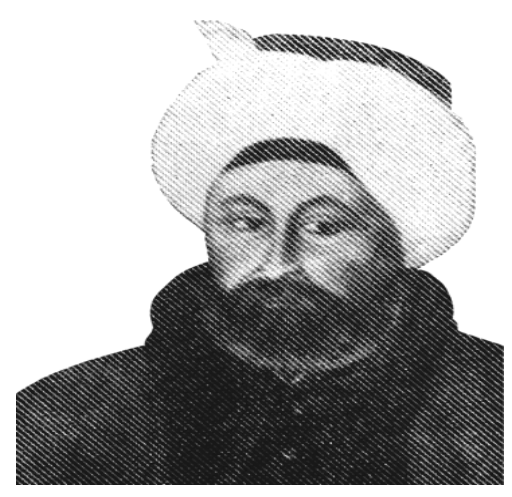

Şekil 1: Mustafa Behçet Efendi [7]

Fizyoloji tarihinden söz ederken yine birçok eser çevirmiş olan Şanizade Mehmed Ataullah Efendi'den de bahsetmek gerekmektedir. Yapmış olduğu çeviriler sayesinde ülkemize modern çiçek aşısı yöntemini getirmiştir [8]. O zamanlar Türkiye'de henüz orijinal eserler çıkarılmamıştı. Bunun nedeniyse yeteri kadar deney yapılamamasıydı [6].

19. yüzyılın ortalarında Avrupa'da bilimin ilerlemesi ve fizyoloji alanında yapılan çalışmaların artmasıyla birlikte bu gelişmeleri takip edebilmek amacıyla öğrenciler, yurt dışına gönderilmeye başlanmıştır. Bu öğrencilerden biriyse Mehmed Şakir'dir [6]. 1849 yılında dünyaya gelen Mehmed Şakir, Türk Fizyoloji tarihindeki önemli isimlerden bir tanesidir. 1871' de Askeri Tıp Okulundan mezun olan Mehmed Şakir, Paris'e dahiliye ihtisasını yapmak üzere gönderilmiştir. Paris Tıp Fakültesi Dekanı intisas için fizyolojinin çok iyi bilinmesi gerektiğini düşünmekteydi ve bu yüzden Mehmed Şakir'i deneysel fizyolojinin kurucusu olan ünlü Fransız bilim insanı Claude Bernand'ın yanına eğitim alması için göndermiştir $[6,9,10]$.

Mehmed Şakir ülkesine döndüğünde fizyoloji kürsüsünü kurmuştur. Böylece Türkiye'de deneysel fizyolojinin temelini atmıştır. Prof. Dr. Mehmed Şakir vefat edene kadar Tıp Okulunda eğitim vermeye devam etmiştir [6].

Mehmed Şakir'in öğrencilerinden biri olan Kemal Cenap (Berksoy), Mehmed Şakir'in yanında ilk asistan olarak çalışmıştır [11]. Mehmed Şakir yetenekli öğrencisini çok beğenmiş ve onu her zaman teşvik etmiştir [12]. 1909 yılında Mehmed Şakir vefat etmiştir ve Kemal Cenap Fizyoloji Bölüm Başkanlığı görevini devralmıştır $[11,13]$.
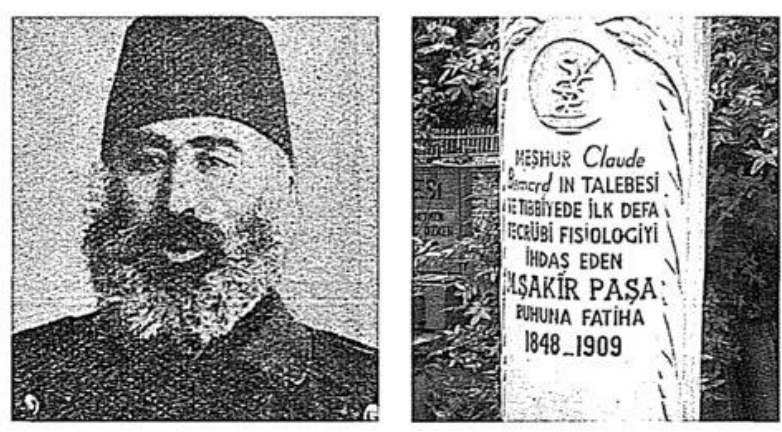

Şekil 2: Şakir Paşa (1848-1909) (B. Şehsuvaroğlu Arşivi) ve Karacaahmet Mezarlığı'nda olan mezar taşı (B. Akgün) [12] 


\section{Kemal Cenap Berksoy'un Hayatı}

Türkiye'de fizyoloji bilim dalının ilerlemesinde öncülük eden isimlerden biri olan Kemal Cenap, babası Hüseyin Cenap Efendi ve annesi Mesnet Hanım'ın 2. çocuğu olarak 1876 yılında Üsküdar'da dünyaya gelmiştir. 1900 yılında ise Kemal Cenap'ın hayatında önemli bir değişiklik olmuştur, Saliha Hanım'la dünya evine girmiş ve bu evliliğinden kızı Bedia (1901), oğlu Seyfi Cenap (1903) dünyaya gelmiştir $[12,14]$.

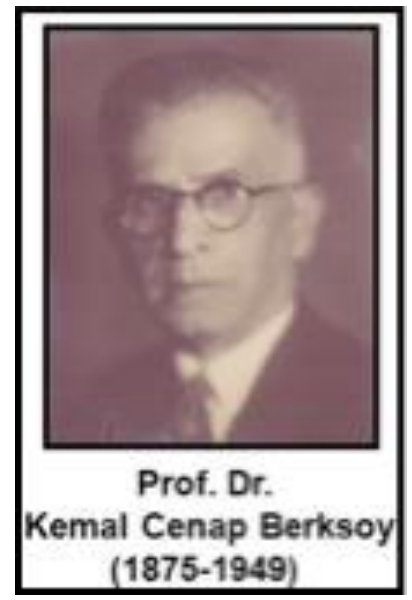

Şekil 3: Kemal Cenap'ın bir fotoğrafı [13]

Kemal Cenap, ilk eğitimini Ahmediye Mahalle Mektebinde almıştır, daha sonra Mekteb-i Rüşdiye-i Askeriyede eğitimine devam etmiştir. Arkasından Askeri Tıbbi İdadisi ve idadinin ardından da Mekteb-i Tıbbiye-i Şahane'yi bitirmiştir. Kemal Cenap, Askeri Tıbbiyeden o esnada süregelen Yunan Harbi nedeniyle zamanından altı ay önce 1897 'de yüzbaşı rütbesi ile mezun olmuştur. Öğrenciliğinde de fizyolojiye meraklı olan Kemal Cenap, Mehmed Şakir'in asistanlığı yapmıştır. Fizyolojihane adı verilen küçük bir laboratuvarda iki yıl boyunca çalışmıştır, çalışmalarııı ardından "muallim muavinliğine" atanmış ve beş yıl sonrasında da muallim-i sani (doçent) olmuştur (1903). Kemal Cenap Mebadi-i Fenn-i Menafi-ül Aza adlı eserini 1905 yılında yayımlamıştır. Bu sırada Tıp Okulu Haydarpaşa'daki yeni binasına taşınmıştır [12,14].

1909 yılında hocasının vefatı üzerine fizyoloji kürsüsüne muallim (profesör) olarak görevine devam etmiştir, aynı yıl Fransa'da bir süreliğine ünlü bilim insanlarının yanında çalışmıştır. Bu sırada askeri ve sivil tıp okulları Haydarpaşa'daki yeni yerinde Tıp Fakültesi adı altında toplanmıştır. Düzenlemeler ile müderris (profesör) unvanı ile devam etmiştir. Ülkesine döndükten sonra Tıp Fakültesinin ilk dekanı olan Cemil Topuzlu'nun desteği ile iyi teçhizatlı bir laboratuvar kurmuştur. Kemal Cenap, kurmuş olduğu bu laboratuvarda o dönemde ülkemizde yapılmamış olan deneyleri sınılı olanaklara rağmen gerçekleştirmiştir. Burada gerçekleştirmiş olduğu deneyleri ve elde etmiş olduğu bilgileri 1914 yılında yayımlanan kitabında aktarmıştır [12,14].

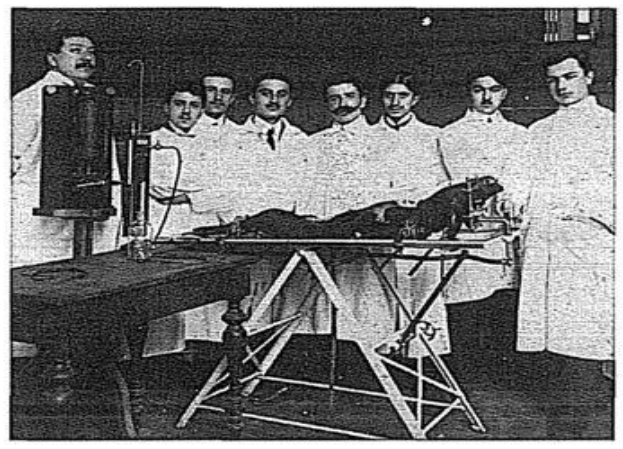

Şekil 4: 1914 yılında bir deney sırasında Kemal Cenap (sağdan dördüncü) ve muavini Talha Bey (solda en baştaki) öğrencileriyle birlikte (CTF Arşivi) [12] 


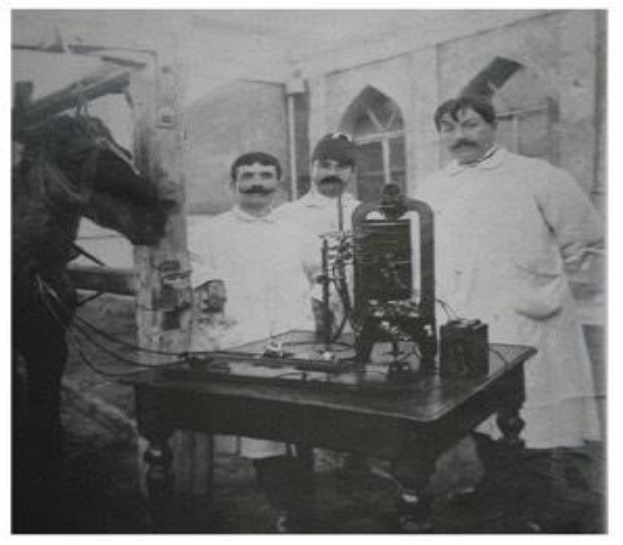

Şekil 5: 1912 yılında fakülte avlusunda yapılan bir deney sırasında Kemal Cenap (en soldaki) [14]

Kemal Cenap, 1912 yılında Balkan Savaşları'nda Edirne'de hekimlik yapmıştır. 1914-1918 yılları arasında tüm dünyayı etkisi altına alan Birinci Dünya Savaşı sırasında ailesiyle Almanya'ya giden ve burada da eğitimine devam eden Kemal Cenap, Berlin'de Bickel, Kramer, Neuberg ve Boruttau gibi isimlerle birlikte elektrokardiyografi ve elektrofizyoloji alanlarında çalışmıştır. Ülkemize döndükten sonra Almanya'da edinmiş olduğu tecrübeler ve bilgiler ile "Fizyoloji Laboratuvar Rehberi” adlı kitabını yazmıştır $[12,14]$.

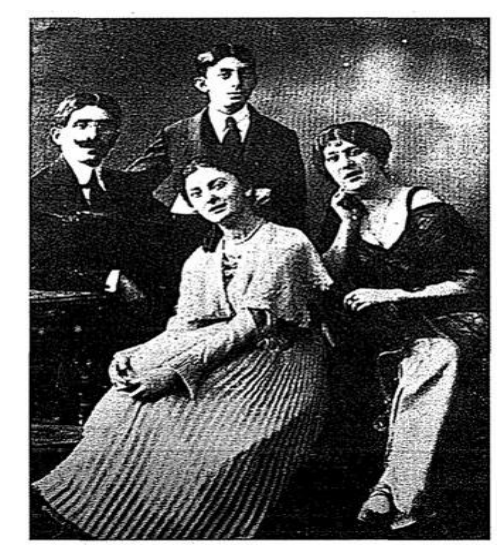

Şekil 6: 1917 yılında Almanya'da Kemal Cenap ve ailesinin çekilmiş bir fotoğrafı [12]

Öğrencileri Kemal Cenap'ın derslerine o kadar çok önem veriyorlardı ki 1919 yılında rahatsızlığı nedeniyle bir süre derse giremediği için muavini tarafından verilen dersler öğrencilerini tatmin etmemiştir. Öyle ki bir önceki yıl bu dersi Kemal Cenap'tan alamayan öğrenciler, Kemal Cenap 2. sınıflara fizyoloji dersini verirken derse girebilmek için izin almışlardır. Ancak bu sefer de 2. sınıflar ve 3. sınıflar arasında ders sırasında ön sıraya oturamadıkları gerekçesiyle tartışma çıkmıştır. Askeri müdahaleyi gerektiren tartışma sonucunda, 3. sınıfların dersi alma izinleri kaldırılmıştır [12].

1920'de İstanbul'un işgal edilmesiyle birlikte İngiliz taburları Tıp Fakültesi'nin ön cephesini tutmuşlardır. Hem öğrenciler hem de öğretmenler zor dönemler yaşamalarına rağmen derslere ara vermeden devam edilmiştir. Derslerin akışını engelleyebilmek ve öğrencileri ruhsal olarak sarsmak için ders saatleri sırasında İngiliz bando takımları alıştırma yapmıştır. Bando takımlarının alıştırma yaptığı bir günde gürültüden dolayı Kemal Cenap sesini sınıfa duyurmakta güçlük çekmiştir ve ardından "Efendiler. Hürriyetsizlik ne kötü ne dayanılmaz şey. Kendi memleketinizde, üniversitenizde bile bir dersi rahatça dinleyemiyorsunuz..." demiştir [12].

Kemal Cenap, akademisyenlik hayatında döneminin ileri hareketlerinden birini daha gerçekleştirmiştir. Yazdığı kitaplardaki bilgileri sürekli güncellemeye özen göstermiş ve böylece öğrencilerinin ders kitabı gereksinimlerini de karşılamıştır. Dönem sonunda gerçekleştirdiği veda konuşmaları sayesinde 
öğrencileriyle kaynaşabilmiştir. Kemal Cenap, öğrencilerince saygı gösterilen ve çok sevilen bir akademisyen olarak hayatını yaşamıştır. [12].

1922-1923 yıllarında ilk kız öğrencinin Tıp Fakültesine alınmasına yardım etmiştir. Bunun için Müderris Meclisine bir konuşma yapmıştır. Konuşmada "Kadınların tahsili içtimai ve mühim bir meseledir. Hukuk fakültesi de bayan talebe kabulüne karar vermiştir. Bizim de bu konuda mücadele etmemiz gerekir. Neden erkek ve kadın bir sırada oturup okumasın?" demiştir [12,14].

Ünlü Rus bilim insanı Pavlov'un gerçekleştirmiş olduğu şartlı refleks deneylerini Kemal Cenap da kendi laboratuvarında başarıyla tekrarlamıştır. Deneyimlerine ve araştırma sonuçlarına, yazmış olduğu kitabında yer vermiştir. 1933 yılında üniversite reformu yapılmıştır ve Kemal Cenap'ında içinde yer aldığı 157 hoca kadro dışı bırakılmıştır [12]. Bir yıl sonrasında, Kemal Cenap'ın derslere gelememesi öğrenciler tarafından boykot edilmiştir. Öyle ki, öğrenciler önce derse girmemeye karar vermiştir ama yeterli dikkati çekemeyince, Atatürk'e mektup yazmaya karar vermiştir. Öğrencilerin mektubundan on gün sonra Atatürk'ün kendisinden Kemal Cenap'a bir mektup gönderilmiş daha sonrasında da üniversitenin rektörü olan Neşet Ömer Bey, Fizyoloji Enstitüsü'nü iki ayırmıştır [12,15]. Beşeri ve Genel Fizyoloji olarak iki enstitü kurulmuştur. Beşeri Fizyoloji'nin başına Kemal Cenap ordinaryüs profesör olarak geçmiştir. Aynı dönemde, Tıp Fakültesi'nin yeri değiştirilmiş ve Haydarpaşa'dan Beyazıt'taki kullanılmayan Harbiye Nezareti binasına taşınmıştır. Genel Fizyoloji Enstitüsü'nün başına Alman bilim insanı Hans Winterstein getirilmiştir. Fizyoloji Enstitüsü iki farklı enstitüye ayrılsa dahi ekipman eksikliğinden dolayı varolan ekipmanların birlikte kullanılması gereken durumlar olmuştur. $\mathrm{Bu}$ konu hakkında, Winterstein şöyle demiştir; "...Şimdi müşterek enstitümüz uydurma bir temel üzerine ikiye bölünmüş fakat tam ayrılamamıştır. Kemal Cenap'ın kısmı nispeten iyi teçhiz edilmiş, benimki ise boş odalardan ibaretti. Ders tecrübeleri için her aleti ödünç olarak almağa mecburdum" [12].

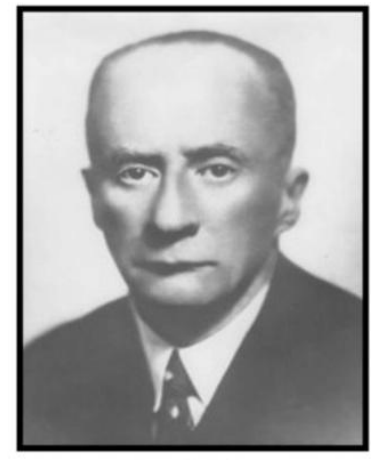

Prof. Dr.

Hans Winterstein

(1878-1963)

Şekil 7: Hans Winterstein'in bir fotoğrafı [16]

Kemal Cenap, 1935 yılında Rusya'daki bir şehir olan St. Petersburg'da (Leningrad) gerçekleşen Uluslararası Fizyoloji Kongresi'ne bildiri sunmak için katılmıştır. Burada bulunduğu sırada rahatsızlanmıştır ve hastanede yatması gereken bir ameliyat geçirmiştir. Bildiri sunma zamanı geldiğine kongreye katılmak için doktorundan izin istemiş ancak doktoru izin vermeyince "hükümetim beni bu iş için gönderdi, ölsem gideceğim" diyerek diretmiştir. Onun üzerine doktoru "Bırakınız, Türkler ölürler ama vazifelerini yaparlar. Bu böyledir menedemeyiz." demiştir. Bildirisinde ise son keşfettiği gastroduodenal refleks hakkında bilgi vermiştir [14].

1943 yılında Ord. Prof. Dr. Kemal Cenap Berksoy emekliye ayrılmıştır. Kemal Cenap'ın emekli olması ile ikiye ayrılan Fizyoloji Enstitüleri yeniden birleştirilmiştir [14].

\section{Kemal Cenap'ın Çalışmaları ve Eserleri}

Kemal Cenap'ın gerçekleştirmiş olduğu araştırmalar hem Türkiye'de hem de yurt dışında oldukça ses getirmiştir ki bu araştırmalar Türkçe, Almanca ve Fransızca olarak 27 makalede yayımlanmıştır [14]. 
Kemal Cenap, en önemli çalışmalarından birini sekretin hormonu üzerine yapmıştır. Bayliss ve Starlin tarafından 1902 yılında keşfedilmiş ve isimlendirilmiş olan sekretinin, 1916 yılında Kemal Cenap tarafından gerçekleştirilen deneylerle pankreas tarafından salgılanan miktarı ölçülmüş ve kıyaslama sonrası en etkili sekretin salınımını gerçekleştiren kısmın, duodenumun derin mukoza tabakası olduğunu keşfetmiştir. Karaciğerin ise bağırsaktan gelen sekretin için hem depo hem de düzenleyici olan bir organ olduğunu öne sürmüştür. Salgılanan sekretin miktarının besinlerle ilişkili olduğunu ve yağlı besinler tüketildiğinde daha çok sekretin salgılandığını keşfetmiştir. Yapmış olduğu bu çalışmalar oldukça ses getirmiş, yurt dışında dahi birçok araştırmacı tarafından yapılan çalışmalarda Kemal Cenap'a atıfta bulunulmuştur. 1921 yılında Souza tarafından Archives Internationales de Physiologie dergisinde yayımlanan yazısında da Kemal Cenap'a atıfta bulunulmuştur [12].

Diğer bir önemli çalışmasını ise kalp fizyolojisi üzerine yapmıştır. Bu çalışmayı Anatomi Profesörü Mouchet ile yürütmüştür. Bu çalışmada o yıllarda oldukça fazla uygulanan doğrudan kalp içerisine enjeksiyonla ilaç verilmesi ve ayrı bir toplardamara enjeksiyonla ilaç verilmesi arasında anlamlı bir fark olmadığını, ikinci uygulamanın daha güvenli bir uygulama olması nedeniyle ilk uygulamanın sadece kalp durması durumunda yapılmasını önermişlerdir. Mouchet ile yürüttükleri başka bir çalışmadaysa günümüzde atriyal natriüretik faktör olarak bilinen hormonu keşfetmişler ve bu hormona "kalp hormonu" ismini vermişlerdir. Bu keşifleri kısa sürede bilim camiasında oldukça ses getirmiştir [12,14].

1918 yılında Almanya'da Neuberg ile çalıştığı dönemde sakkarofosfataz ismini vermiş oldukları, bira mayasında olan yeni bir fermentin varlığını saptamışlardır. Kemal Cenap'ın son çalışması 1940 yılında yapmış olduğu köpekte tütün zehirlenmesi çalışması olmuştur [12].

Kemal Cenap'ın yazmış olduğu kitapları kronolojik olarak aşağıdaki gibi sıralamak mümkündür [12];

1. 'Mebâdî-i Fenn-i Menafiü'l-âzâ. İstanbul 1321/1905.

2. Fizyoloji yahud Fenn-i Vezâllü'l-âzâ. İstanbul 1325/1909.

3. Fizyoloji. Hazım Bahsi. İstanbul 1325/1909.

4. Fizyoloji-i Nazarî Dersleri 1. Kitap. İstanbul 1325/1909.

5. Fizyoloji-i Nazarî Dersleri 2. Kitap. İstanbul 1325/1909.

6. Amelî Fizyoloji Dersleri. İstanbul 1326/1909.

7. Fizyolojii Griziyat (İkinci Tabı). İstanbul 1330/1914.

8. Fizyoloji Laboratuvar Rehberi. Kimya-ı Fiziyoloji. İstanbul 1335/1919.

9. İnsan Teşrih Modeli Erkek. İstanbul, 1934.

10. İnsan Teşrih Modeli Kadın. İstanbul, 1934.

11. Füsiologi (Birinci Kısım). İstanbul, 1934.

12. Insan Anatomi Modeli ve Terimleri Erkek. (Zeki Zeren ile) İstanbul, 1938.

13. İnsan Anatomi Modeli ve Terimleri Kadın. (Zeki Zeren ile) İstanbul, 1938.

14. Beşeri Fizyoloji Ders Kitabı (Birinci Cilt). İstanbul, 1941.

15. Beşeri Fizyoloji Ders Kitabı (İkinci Cilt). İstanbul, 1943."

Bu eserler arasındaki Füsiologi adlı eserinde yazmış olduğu çalışmalar oldukça ses getirmiştir. Öyle ki, bu eserde daha sonra bahsedeceği endokrin sekresyonu ile ilgili çalışmaları nedeniyle Nobel Fizyoloji ve Tıp Ödülleri'ne 1932 yılında aday gösterilmiştir. Kemal Cenap ön değerlendirilmeden geçmiştir ve Nobel Fizyoloji ve Tıp Ödülleri için aday gösterilen 111 kişiden biri olmuştur. Kemal Cenap o yıl ödülü kazanamamıştır ancak 1942 yılında verilecek ödül için aday gösterici olarak davet edilmiştir. 1901 yılından 1951 yılına kadarki elli yıllık süreçte Nobel Fizyoloji ve Tıp Ödülleri'ne aday gösterilen ilk ve tek Türk bilim insanı olmuştur $[12,14]$. 


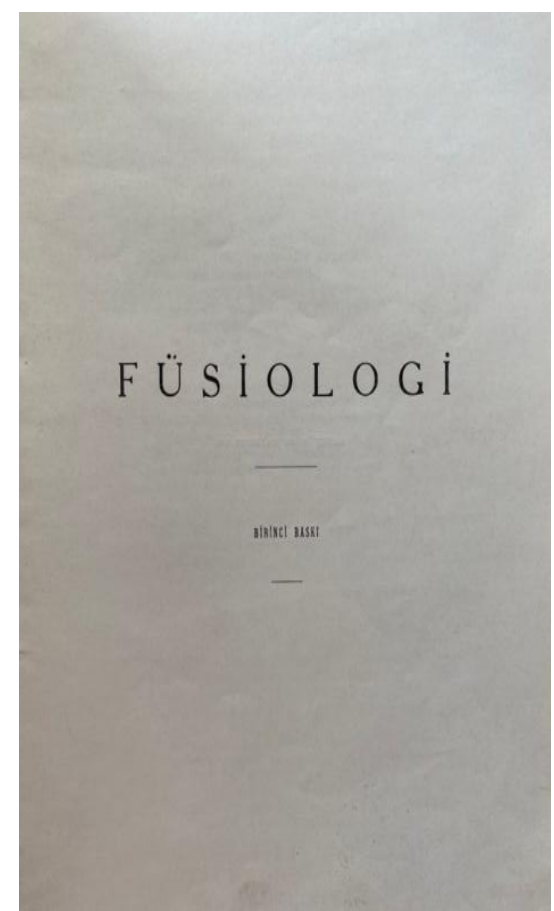

Şekil 8: Kemal Cenap'ın yazmış olduğu

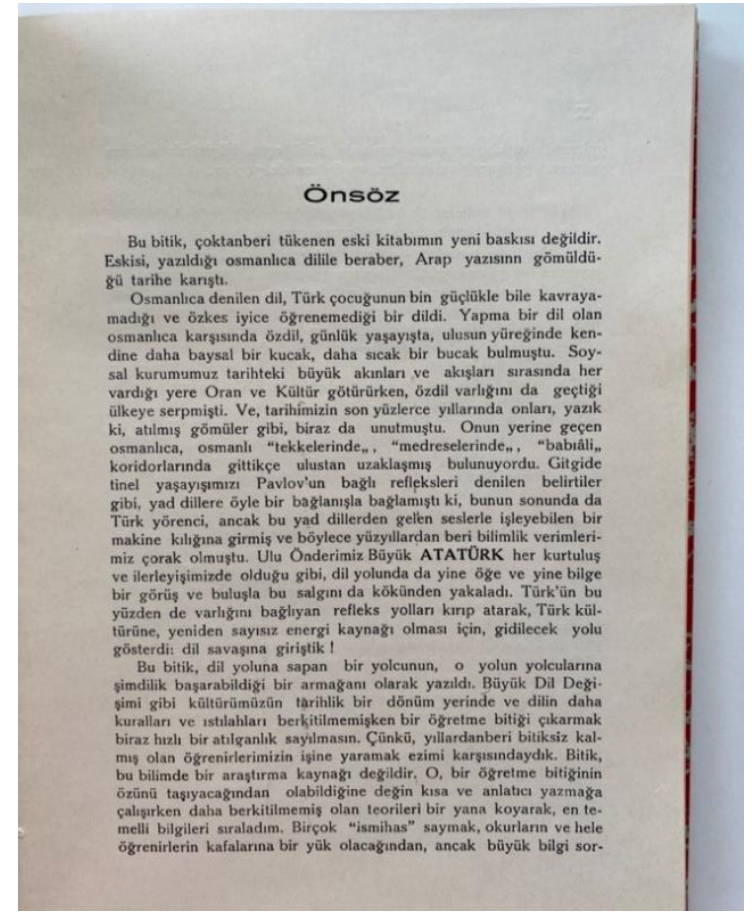

Şekil 9: Füsiologi kitabının önsözü [17]

Füsiologi kitabının iç kapağı [17]

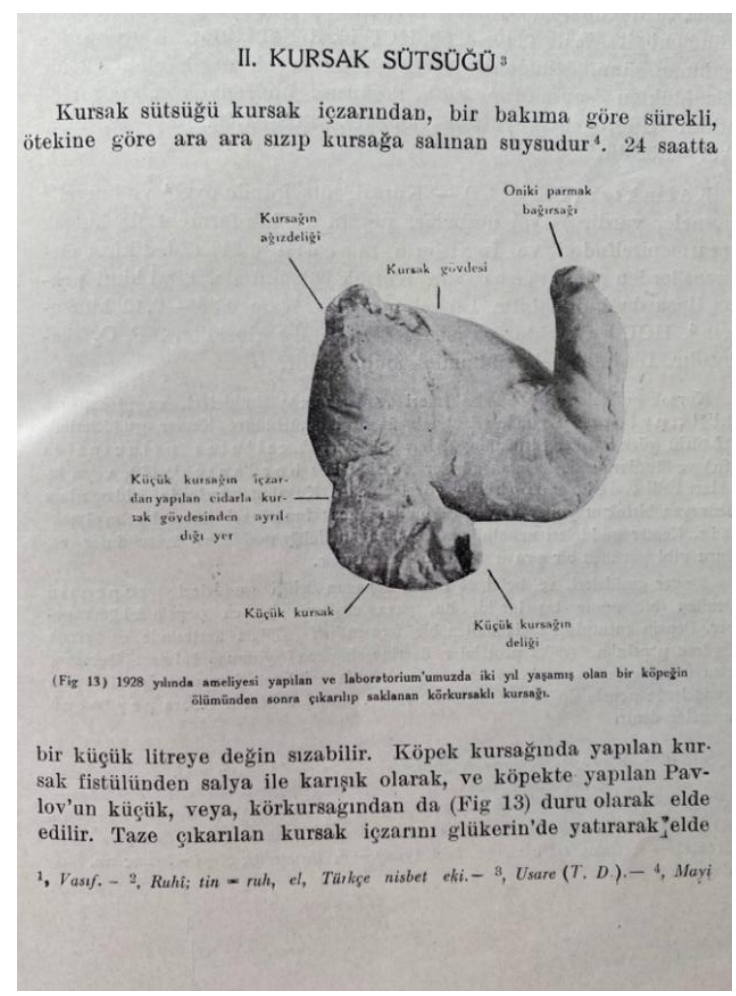

Şekil 10: Mide özsuyunun salgılanmasının Kemal Cenap tarafından görselle anlatılması (Füsiologi kitabı) [17] 


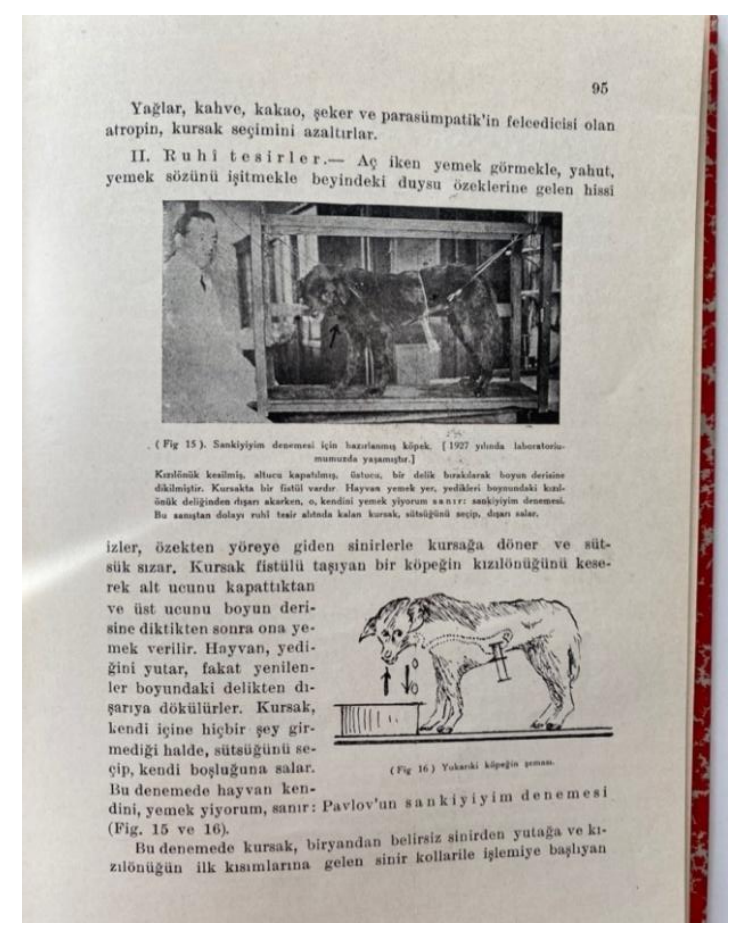

Şekil 11: Kemal Cenap'ın Pavlov'un deneyini tekrar edişinin fotoğrafı ve çizimi (Füsiologi kitabı) [17]

\section{Kemal Cenap'ın Diğer Çalışmaları (Dil Devrimi'ndeki Çalışmaları)}

Kemal Cenap dil devriminden önce Osmanlıca ve Fransızca sözcüklerin kaldırılıp yerini Latince sözcüklere bırakılması gerektiğini öne sürmüştür [18]. 1932 yılında Türk Dil Kurumu kurulmuştur ve dilimizden yabancı kelimelerin kaldırılması için çalışmalar yapılmaya başlanmıştır. Bu yabancı kelimelerin Türkçe karşııılarını bulabilmek için 1937-1938 yıllarında çalışmalara başlanmıştır [19].

Bu konuda önderlik yapan kişilerden biri olan Kemal Cenap'ın dil devrimine desteği yadsınamaz, öyle ki üniversite reformu esnasında devam etmekte olan dil devrimi için Türkçe bilim terimleri hakkında son derece hızlı çalışmalar yapmıştır $[12,19]$.

Ayrıca 1934 yılında yayımlanmış olan İnsan Teşrih Modeli - Erkek ve İnsan Teşrih Modeli-Kadın adlı kitaplarında, vücut organlarına karşılık olabilmesi için Türkçe kelimeler önermiştir [19].

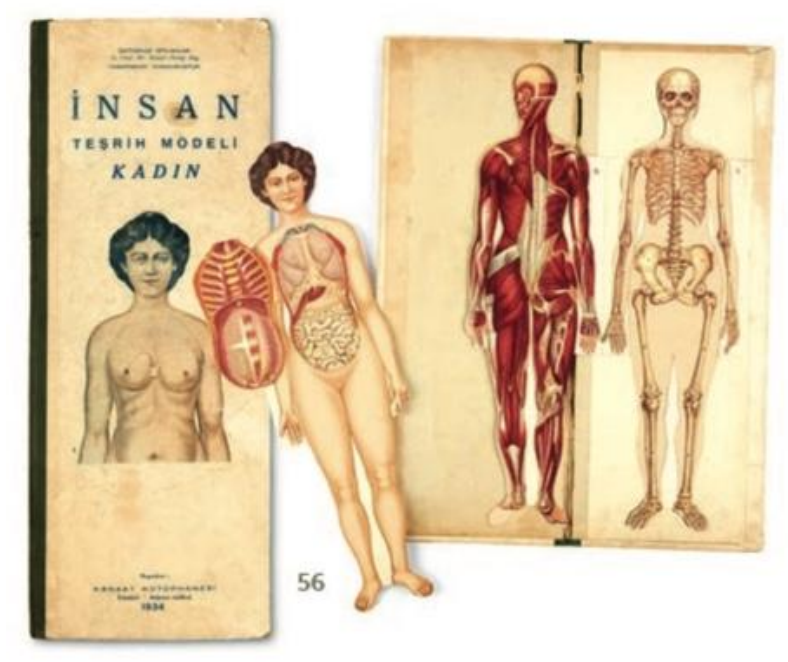

Şekil 12: 1934 yılında yayımlanmış olan İnsan Teşrih Modeli-Kadın [20] 


\section{Kemal Cenap'ın Emeklilik Yılları ve Vefatı}

1943 yılında Kemal Cenap yaş haddinden dolayı emekli olmuştur. Emeklilik sonrasında Cumhuriyet gazetesine bir ilan vermiştir. Bu ilanda;

“ikmale Kalan Tıp Talebelerine,

Prof. Dr. Kemal Cenab Fizyoloji dersinden eylûl devresi ikmal imtihanlarına kadar talebeden arzu edenleri hususi derslerle Taksim Doğupalas apartmanındaki dairesinde yetiştirmeyi kabul ediyor.

Tel: 43963" [21].

Emeklilik sonrasında bile tıp öğrencilerine yeni bilgiler öğretmeye, onları çalıştırmaya istekli olmuş olan Kemal Cenap, akademik yaşamı boyunca öğrencileri tarafından sevilen ve sayılan biri olmuştur.

Çalışırken en düşük seviyede maaş almış olan Kemal Cenap'ın emeklilik maaşının da düşük olması ve muayenehanesine de çok fazla hasta gelmemesi nedeniyle Kemal Cenap maddi sorunlar yaşamıştır. 1944 yılında İstanbul milletvekili olan Mehmet Emin Yurdakul'un vefatı üzerine boşalan milletvekili koltuğuna Nisan 1944'te Kemal Cenap seçilmiştir. Böylece bir miktar da olsa maddi sorunlarından kurtulmuştur. 1946 yılında yapılan seçimde ise bu sefer Yozgat milletvekili olarak seçilmiştir. Vefatına kadar bu görevi sürdürmüştür.

Kemal Cenap yaşamı boyunca birçok sağlık sorunu yaşamıştır. 1924 ve 1926 yıllarında iki kez tedavi edilmesi için yurt dışına gönderilmiştir. 1935 yılında da Moskova'da ameliyat edilmiştir. Eski öğrencileri Kemal Cenap için "...Fakülte hocalarının en yaşlısı olduğu halde dinç görünür, buna rağmen basil çıkartan bir TBC'li olarak rahatlıkla dolaşır, haftada bir gün bakteriyoloji laboratuarına uğrayarak kraşa (balgam) muayenesi yaptırır..." diye yazmıştırlar.

1946 yılındaki milletvekili seçiminde tekrar seçilmesinden sonra yavaş ilerleyen bir beyin hastalığına yakalanmıştır. 28 Kasım 1949 yılında Ankara'da Hakk'ın rahmetine kavuşmuştur. 7 Aralık 1949 yılında Büyük Millet Meclisi toplantısı esnasında iki dakikalık saygı duruşunda bulunulmuştur [12].

\section{Tartışma ve Sonuç}

Hücreden sisteme doğru canlının yaşamsal işlevlerini inceleyen fizyoloji bilimi, tıp alanındaki gelişme ve keşiflere önayak olmuştur. Türkiye'de 19. yüzyılda başlayan bu alandaki çağdaşlaşma çalışmaları için Berksoy'un sunduğu katkılar yadsınamaz. Ordinaryüs Profesör Doktor Kemal Cenap Berksoy'un yaşamı ve çalışmaları nezdinde Türk Fizyolojisinin gelişim evrelerini görmek ve bu süreçlerdeki bağıntıları anlamlandırmak mümkündür. Kendi hocalarından etkilenme süreci ile başlayan fizyoloji serüvenini, bir sisteme oturtmak ve kendinden sonra gelen öğrenciler ve araştırmaçlar için kaynak oluşturmak adına yaşamı boyunca yaptığı çalışmalarla bilim tarihimizde kendisine yer edinmiştir. Akademik yaşamındaki deneyimleri ve bakış açısını toplumsallaştırmak adına siyasi tarihimizde de bir figür olarak karşımıza çıkmaktadır. Tüm bunların yanında bilimsel ve çağdaş yöntemlerle yetiştirilmesine katkı sunduğu öğrencileri aracılığıyla modern fizyoloji öğretilerinin ülkemizde yayılmasında etkili olmuştur. Berksoy'dan önce Avrupa'daki çalışmalara öykünme ve bu çalışmaları takip etme düşüncesi yaygınken, Berksoy'un çalışmalarının Avrupa'daki birçok çalışmada kaynak gösterilmesi ile bilim dünyamızda öncü olma güdüsü gelişmiştir. Berksoy sadece Türkiye'de değil dünya biliminde de çalışmalarıyla ses getirmiştir. Bu etkisi 1931 yılında Nobel Fizyoloji ve Tıp Ödülleri'ne aday gösterilmesiyle taçlanmıştır. Gerek yetiştirdiği öğrenciler ve yaptığı uluslararası çalışmalar gerekse toplumsal ve siyasal alanlarda görevler alması yönüyle Berksoy modern bilim tarihimizin en renkli figürlerinden biri olmuştur. Türkiye'deki modern fizyolojinin gelişim evrelerini anlamlandırabilmek adına Berksoy'un tanınması olumlu bir etki sağlayacaktır.

\section{Kaynakça}

[1] Boulpaep EL, Boron WF. In Boron WF, Boulpaed L. Medical physiology E-book.: Elsevier Health Sciences; 2016. p. 2-5.

[2] Pocock, Gillian. Basic Concepts In Physiology. In Pocock G, Richards CD, Richards DA. Human Physiology.: Oxford University Press; 2013. p. 3-27. 
[3] Ağar, Erdal; Dinçer, Sibel; Kurdak, Sanlı Sadi. İnsan Fizyolojisi İstanbul: İstanbul Tıp Kitapevleri; 2021.

[4] Türk Fizyolojik Bilimler Derneği. [Online]. [cited 2021 Mayıs 27. Available from: https://www.tfbd.org.tr/fizyoloji-nedir.

[5] Erdem DDA, Basralı PDF, Şemin PDI, Uzuner PDK, Bor-Küçükatay PDM, Tuncer DDM, et al. Türk Fizyolojik Bilimler Derneği. 2013 Mart.

[6] Kahya E. Osmanlı İmparatorluğunda Deneysel Fizyolojinin Kuruluşu. 1991.

[7] Atalık K. Hekimbaşı Mustafa Behçet Efendi. Nobel Medicus. ; 10(1).

[8] Ülman Işıl DDY. "Türkiye'de 19. ve 20 yüzyıllarda Tıp Tarihinin Anahatları." Tıp Tarihi ve Tıp Etigi Ders Kitabı İstanbul; 2007.

[9] Erdemir Demirhan PDA. Türk Tıp Tarihinde 19. Yüzyılda ve Cumhuriyet Döneminde On İki Türk Hekimi ve Bazı Sonuçlar. Türk Dünyası Araştırmaları Vakfı. 2019 Temmuz- Ağustos: p. 281-292.

[10] Lee JA. Claude Bernard(1813-1878). 1978: p. 741-747.

[11] Yılmaz PDB. [Türk Fizyolojik Bilimler Derneği e-Bülten].; 2016.

[12] Akgün UDB. Üsküdarlı Bir Hekim: Ord. Prof. Dr. Kemal Cenap Berksoy. In Uluslararası Üsküdar Sempozyumu; 2008; İstanbul. p. 439-456.

[13] Yılmaz PDB. Fizyoloji Ders Kitaplarının 100 Yılı. Türk Fizyolojik Bilimler Derneği. 2016 Nisan- MayısHaziran: p. 1-3.

[14] Yasinoğlu E."1901-1951 Yıllan Arasında Nobel Fizyoloji ve Tıp Ödülleri'ne Aday Gösterilen İlk ve Tek Türk Bilim Adamı, Türk Fizyoloji Tarihinin Unutulmaz Hocası." Nobel Medicus Journal. 2017; 13(2).

[15] Etker Ş. Darülfünun'a Mersiye. Osmanlı Bilimi Araştırmaları. 2016: p. 42-55.

[16] Özden PDA. Türk Tıbbının Tarihi. Güncel Gastroenteroloji. 2017 Aralık: p. 251-256.

[17] Berksoy KC. Füsiologi. 1st ed. İstanbul; 1934.

[18] Ülker PDS. Tıp Dili Türkçeleştirme Çalışmları. In 1. Türkçe Tıp Dili Bilimsel Toplantısı; 2019; İzmir. p. 87-91.

[19] Kemahlı PDS. Tıp Eğitimi Ve Hekimlik Dilimiz Nasıl Türkçeleşti? 2015: p. 5-12.

[20] Alif Art. [Online].; 2019 [cited 2021 Haziran 6. Available from: https://www.alifart.com/orta-mektep-ve-lisetalebesi-ile-universite-tip-ve-fen-fakulteleri-talebesine-fa/

[21] Yaprak M. Profesör Doktor Kemal Cenap Berksoy'un 1943 Yılında Verdiği Bir Gazete İlanı. Mersin Üniversitesi Tıp Fakültesi Lokman Hekim Tıp Tarihi ve Folklorik Tıp Dergisi. 2013 Mayıs: p. 24-24. 